\title{
Analisis Uji Balistik Komposit Serat Pelepah Salak Dengan Resin Epoksi dan Silicon Carbida (SiC) Menggunakan Metode Vacuum Bag
}

\author{
(Ballistic Test Analysis Of Salak Fiber Composite With Epoxy \\ Resin And Silicon Carbide (SiC) Using Vacuum Bag Method)
}

\author{
Rivaldy Armando Kamal ${ }^{1 *}$, Muhammad Abdul Ghofur ${ }^{2}$, Nur Priyanto Poupon ${ }^{3}$ \\ 1,2,3 Program Studi Teknik Aeronautika Pertahanan, Akademi Angkatan Udara \\ E-mail:rivaldykamal.ptta5@gmail.com,m_abdulghofur@aau.ac.id,nurpriyantopoupon@yahoo.com
}

\begin{abstract}
Composites are two kinds of materials or more which are combined on a macroscopic scale (can be seen directly by the eye) become new and more useful materials. This research was carried out to make a natural fiber reinforced composite material, namely salak midrib which can be used as a substitute for metal materials that applied in Indonesian Air Force defense equipment such as bullet-proof vests. This study aims to determine the mechanical properties in the form of tensile strength and hardness values of salak fiber composites and to determine the ballistic strength of a composite fired with $9 \mathrm{~mm}$ caliber bullets (MU-1TJ) with several variations of firing distance according to NIJ standards using Precision Shooting Test Equipment. The manufacture of this composite used the Vacuum Bag composite method. The result of the test confirmed that the mechanical properties of the salak midrib fiber composite are in the form of a tensile strength is 21.46 $\mathrm{N} / \mathrm{mm} 2$ and the hardness value is $23.64 \mathrm{HV}$. The results of the ballistic test found 2 specimens that fulfill the NIJ standard and 2 specimens that did not satisfy the NIJ standard. The first specimen that occupy the NIJ level IIA standard is a composite specimen with the composition of Kevlar and SiC Filler, where the results from a shooting distance of $30 \mathrm{~mm}$ have a BFS of $6.26 \mathrm{~mm}$, a distance of $25 \mathrm{~m}$ has a BFS of $11.86 \mathrm{~mm}$, a distance of $10 \mathrm{~m}$ and $5 \mathrm{~m}$ bullets penetrate the specimen. The second specimen that fulfill NIJ level II and IIA standards is a hybrid composite specimen with a composition of blended bark fiber, kevlar fiber, SiC and Al7075-T6 fillers, where the results of firing at a distance of $30 \mathrm{~mm}$ have a BFS of $0 \mathrm{~mm}$, a distance of $25 \mathrm{~m}$ has a BFS of $0 \mathrm{~mm}$, a distance of $10 \mathrm{~m}$ has a BFS of $0 \mathrm{~mm}$ and a distance of $5 \mathrm{~m}$ has a BFS of $0 \mathrm{~mm}$ (all bullets did not penetrate the specimen).
\end{abstract}

Keywords - Composite, Salak Midrib Fiber, Kevlar Fiber, SiC Filler, Vacuum Bag Method

Abstrak- Komposit adalah dua macam atau lebih material yang digabungkan dalam sekala makroskopis (dapat terlihat langsung oleh mata) sehingga menjadi material baru yang lebih berguna. Penelitian ini dilaksanakan untuk membuat material komposit berpenguat serat alam yaitu serat pelepah salak yang mampu dimanfaatkan sebagai pengganti material logam yang digunakan pada alutsista TNI AU seperti rompi anti peluru. Penelitian ini bertujuan untuk mengetahui sifat mekanis berupa kekuatan tarik dan nilai kekerasan dari komposit serat salak serta mengetahui kekuatan balistik dari sebuah komposit yang ditembakkan dengan peluru kaliber $9 \mathrm{~mm}$ (MU-1TJ) dengan beberapa variasi jarak penembakan sesuai standar NIJ menggunakan Alat Uji Tembak Presisi. Pembuatan komposit ini menggunakan metode komposit Vacuum Bag. Dari hasil pengujian diperoleh

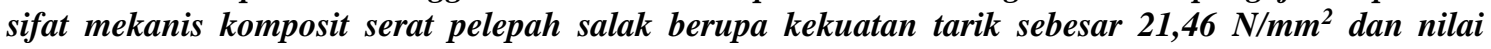
kekerasan salak sebesar 23,64 HV. Hasil dari pengujian balistik terdapat 2 spesimen yang memenuhi standar NIJ dan 2 spesimen yang tidak memenuhi standar NIJ. Spesimen pertama yang memenuhi

\footnotetext{
* Penulis Korespondensi (Rivaldy Armando Kamal)
}

E-mail: rivaldykamal.ptta5@gmail.com 
standar NIJ level IIA adalah spesimen komposit dengan komposisi kevlar dan Filler SiC, dimana hasil penembakan jarak $30 \mathrm{~mm}$ memiliki BFS 6,26 mm, jarak 25 m memiliki BFS 11,86 mm, jarak $10 \mathrm{~m}$ dan 5 m peluru menembus spesimen. Spesimen kedua yang memenuhi standar NIJ level II dan IIA adalah spesimen komposit hybrid dengan komposisi perbaduan serat pelepah salak, serat kevlar, filler SiC dan Al7075-T6, dimana hasil penembakan jarak 30 mm memiliki BFS 0 mm, jarak 25 m memiliki BFS 0 mm, jarak $10 \mathrm{~m}$ memiliki BFS 0 mm dan jarak 5 m memiliki BFS 0 mm (semua peluru tidak menembus spesimen).

Kata Kunci_ Komposit, Serat Pelepah Salak, Serat Kevlar, Filler SiC, Metode Vacuum Bag

\section{PENDAHULUAN}

$\mathrm{K}$ ebutuhan alat pelindung tembakan bagi prajurit TNI-Polri sangat penting. Hal itu diindikasikan dengan perintah perintah untuk menumpas terorisme dan separatisme, misalnya di Papua. Salah satu alat pelindung tembakan yang lazim dipakai oleh prajurit yang bertugas adalah rompi anti peluru. Di dalam rompi anti peluru tersebut terdapat material yang melapisi tubuh agar tahan terhadap tembakan. Material tersebut dibuat menggunakan teknik komposit. Selama ini, material komposit pelapis rompi anti peluru diperoleh dengan cara impor dari luar negeri, misalnya yang berbahan dasar logam dan Kevlar. Biaya pengedarannya juga cukup tinggi, sehingga belum semua prajurit yang bertugas terlindung rompi anti peluru.

Dalam industri manufaktur dibutuhkan suatu material yang memiliki sifat-sifat istimewa yang sulit didapat dari logam. Komposit merupakan material alternatif yang dapat digunakan untuk memenuhi kebutuhan tersebut dimana tersusun dari kombinasi dua atau lebih material yang dapat menghasilkan properti atau sifat mekanis yang lebih baik dari pada jika komponen tersebut berdiri sendiri. Keuntungan material komposit adalah kekuatan dan kekakuannya yang tinggi, dikombinasikan dengan density yang rendah. Penggunaan bahan ini dapat menghasilkan material yang ringan, namun memiliki kekuatan yang tinggi [3]. Komposit tersusun atas dua material yaitu matriks dan fiber dimana matriks berfungsi sebagai perekat atau pelindung, sedangkan fiber berfungsi sebagai penguat dan penanggung beban utama pada komposit. Jenis serat pada material komposit terdiri dari serat sintetis dan serat alam. Penggunaan serat alami dalam material komposit merupakan usaha yang dilakukan untuk mengurangi dampak lingkungan karena mudahnya terurai di lingkungan secara alami. Selain itu penggunaan serat alam ini mempunyai beberapa kelebihan antara lain mudah didapat, jumlahnya berlimpah dan dapat diperbaharui [4].

Penelitian Darmanto dkk menunjukkan tentang Karakterisasi Perlakuan Awal Serat Pelepah Salak Untuk Meningkatkan Kekuatan Mekanik. Hasil penelitian tersebut menunjukkan adanya potensi untuk dimanfaatkan oleh para peneliti. Pembuatan material maju berbasis komposit yang diduga menjadi salah satu solusi pembuatan material rompi anti peluru [7]. Berlimpahnya jumlah serat pelepah salak menjadi pertimbangan dalam penelitian ini. Provinsi Daerah Istimewa Yogyakarta memiliki banyak tanaman salak (zallaca edulis, Reinw) sebagai komoditas utama perkebunan bagi para petani khususnya di daerah Sleman. Salah satu jenis perawatan tanaman salak yang dilakukan agar meningkatkan produktivitas nya sesuai dengan Standar Prosedur Operasional (SPO) Good Agricultural Practices (GAP) yaitu dengan pemangkasan pelepah daun pohon salak. Diperkirakan setiap 4 bulan sekali pelepah pohon salak dilakukan pemotongan sebanyak 3-4 kali, sehinga diperkirakan limbah pelepah salak yang dihasilkan sebanyak 1368 ton/bulan. Dalam satu rumpun tanaman salak (produktif) dapat menghasilkan 24 buah potongan pelepah salak, sehingga apabila dikalkulasikan dengan jumlah pohon salak yang ada maka dalam satu tahun pelepah salak yang belum termanfaatkan sekitar \pm 23.000 truk. Limbah pelepah salak kemudian sebagian dimanfaatkan petani sebagai bahan organik bagi tanaman salak, sebagian di buang begitu saja, dibakar, dan sebagian kecil di buat kerajinan [2]. Pengembangan material jenis komposit ini juga menjadi salah satu Prioritas Riset Nasional Tahun 2020-2024 khusususnya di bidang pertahanan dan kemanan dimana suatu peralatan 
pertahanan dan keamanan memiliki spesifikasi khusus dan tingkat teknologi yang cukup tinggi, sehingga kegiatan penelitian dan pengembangan untuk mewujudkan dan mendorong kemandirian industri pertahanan di bidang tersebut menghadapi tantangan yang cukup besar [22]. Penelitian ini untuk mencari sifat mekanis dan kemampuan balistik dari komposit dengan matriks yang berpenguat serat alam pelepah pohon salak dengan variasi filler menggunakan metode Vacuum Bag.

\section{LANDASAN TEORI}

\section{A. Literature Review}

Azissyukhron dan Hidayat, melakukan penelitian tentang Perbandingan Kekuatan Material Hasil Metode Hand Lay-up dan Metode Vacuum Bag Pada Material Sandwich Composite. Dari hasil peneltian ini, dalam proses pembuatannya menggunakan metode vacuum bag yang menjadi metode penyempurnaan dari metode hand lay-up. Secara umum dalam proses pengerjaannya kedua metode tersebut tidak berbeda jauh, hanya saja pada metode vacuum bag dilakukan proses penyedotan menggunakan alat vakum yang bertujuan untuk menghilangkan resin yang berlebih dan udara yang terperangkap pada laminasi sehingga didapat komposit dengan sifat material yang lebih baik dari komposit hasil metode hand lay-up [1].

Hasyim dan Ghofur melakukan penelitian tentang Analisis Variasi Fraksi Volume Serat Dan Perlakuan Alkali Terhadap Kekuatan Tarik Dan Bending Komposit Serat Sisal. Dari hasil penelitian ini menunjukkan bahwa fraksi volume serat 50\% menghasilkan kekuatan tarik dan bending lebih besar dibanding dengan fraksi volume 30\% dan 10\%. Pengaruh perendaman alkali pada serat selama 6 jam memiliki kekuatan tarik dan bending lebih besar dibanding dengan perendaman 4 jam dan 2 jam [6].

Darmanto, dkk melakukan penelitian tentang Karakterisasi Perlakuan Awal Serat Pelepah Salak Untuk Meningkatkan Kekuatan Mekanik. Hasil pengujian menunjukkan bahwa kekuatan tarik serat bundle pelepah salak dapat mencapai $114 \mathrm{MPa}, 66 \mathrm{MPa}$ dan $189 \mathrm{MPa}$ masing-masing untuk serat bundle tanpa perlakuan, serat bundle dengan perlakuan alkali 5\% dan serat bundle dengan perlakuan kombinasi yakni alkali 5\% yang dilanjutkan dengan pengukusan pada tekanan 5 Bar [7].

Angelia, dkk melakukan penelitian tentang Analisis Kekuatan Tarik, Bending, Mikrostruktur, Komposisi dan Kemampuan Redam Suara Komposit Serat Pelepah Pisang Menggunakan Metode Vacuum Assisted Resin. Dari hasil penelitian ini menunjukkan bahwa kekuatan tegangan tarik yang dihasilkan oleh komposit serat pelepah pisang dengan waktu pengeringan selama 7 hari adalah sebesar $17,90 \mathrm{~N} / \mathrm{mm} 2$ sedangkan waktu pengeringan selama 1 hari adalah sebesar $16,72 \mathrm{~N} / \mathrm{mm} 2$. Kekuatan bending yang dihasilkan oleh komposit serat pelepah pisang dengan waktu pengeringan selama 7 hari adalah sebesar 31,75 N/mm2 [8].

Santos, dkk melakukan penelitian tentang Composites with Natural Fibers and Conventional Materials Applied in a Hard Armor: A Comparison. Hasil penelitian menunjukkan bahwa hard armor dengan bagian depan keramik diikuti oleh komposit serat alam (PALF/epoxy) memenuhi National Institute of Justice (NIJ) internasional standar untuk perlindungan level III waktu pengeringan selama 1 hari adalah sebesar 20,68 N/mm2 [9].

Naveen, dkk melakukan penelitian tentang Ballistic Performance of Natural Fiber Based Soft and Hard Body Armour. Dari hasil penelitiannya menyatakan bahwa penyerapan energi balistik dari komposit serat alam yang diperkuat hampir cocok dengan komposit serat aramid sintetis. Serat alam sistem Armor Multilayer diperoleh kedalaman lekukan yang lebih rendah dibandingkan dengan serat Kevlar [10].

Dalam penelitian ini penulis akan melakukan penelitian dengan menggunakan metode Vacuum Bag, fraksi volume serat diatas $30 \%$. Serat pelepah salak akan mendapat perlakuan 
alkali 5\% dengan waktu perendaman selama 3 jam yang dilanjutkan dengan pengeringan serat pelepah salak di tempat panas. Proses pemotongan dan pengujian spesimen dilaksanakan setelah 7 hari dari mulai pembuatan spesimen. Dilanjutkan mencari sifat mekanis dan sifat fisis dari komposit dengan matrik yang berpenguat serat alam pelepah pohon salak dengan variasi tanpa filler dan ditambah filler Silicon Carbida (SiC) menggunakan metode Vacuum Bag. Kemudian dalam penelitian ini juga dilanjutkan dengan pengujian balistik untuk mengetahui kemampuan balistik serat alam pelepah salak ini.

\section{B. Komposit}

Komposit adalah dua macam atau lebih material yang digabungkan atau dikombinasikan dalam sekala makroskopis (dapat terlihat langsung oleh mata) sehingga menjadi material baru yang lebih berguna. Sifat mekanik bahan komposit seperti kekuatan, kekakuan, keliatan dan ketahanan sangat tergantung dari geometrinya dan sifat-sifat dari jenis penguatnya. Komposit memiliki keunggulan dalam hal ketahanan terhadap aus dan suhu yang tinggi walaupun kekuatan dan ketahanan retaknya lebih rendah, tetapi hal itu dapat diperbaiki dengan penguatan tertentu [16]. Material Penyusun Komposit terdiri atas 2 unsur, yaitu bahan penguat (reinforcement) dan bahan dasar sebagai pengikat yang disebut matriks. Sebagai bahan penguat dapat berupa serat atau partikel.

Material komposit merupakan material non-logam yang saat ini semakin banyak digunakan. Hal ini cukup beralsan mengingat adanya kebutuhan material di samping memprioritaskan sifat mekanik, juga dibutuhkan sifat yang lebih baik, misalnya ringan, tahan korosi, dan ramah lingkungan. Selain itu, sifat teknologi merupakan salah satu sifat yang harus dimiliki oleh material komposit tersebut. Dimana sifat teknologi adalah kemampuan material untuk dibentuk atau diproses. Proses pembuatan atau proses produksi dari komposit tersebut merupaka hal yang sangat penting dalam menghasilkan material komposit. Banyak cara atau metode yang digunakan untuk menghasilkan material komposit yang diinginkan. Proses Vacuum Bag merupakan penyempurnaan dari Hand Lay up. Penggunaan proses vakum ini adalah untuk menghilangkan udara yang terperangkap dan berlebih dalam penggunaan resin. Pada proses ini digunakan pompa vakum untuk menghisap udara dalam wadah diletakkanya komposit yang akan dilakukan proses pencetakan. Artinya, dengan divakumkan udara dalam wadah, maka udara yang ada di luar penutup plastic akan menekan ke arah dalam. Hal ini menyebabkan udara yang terperangkap dalam spesimen komposit dapat minimalkan.

\section{Model YANG DiUSUlKan}

\section{A. Arsitektur Model Secara Umum}

Model yang diusulkan dalam penelitian ini dirancang sebuah material komposit dengan menggunakan serat alam pelepah salak. Proses pembuatan spesimen menggunakan metode Vacuum Bag. Setelah spesimen komposit terbentuk, maka dilakukan uji tarik, uji kekerasan dan uji kemampuan balistik. Pembuatan material komposit, pengujian Tarik dan kekerasan dilakukan di laboratorium Komposit dan Material Teknik Departemen Aeronautika Akademi Angkatan Udara, Yogyakarta sedangkan pengujian kemampuan balistik dilaksanakan di Depohar 60 Madiun.

Vacuum Bag merupakan penyempurnaan dari Hand Lay up. Penggunaan proses vakum ini adalah untuk menghilangkan udara yang terperangkap dan berlebih dalam penggunaan resin. Pada proses ini digunakan pompa vakum untuk menghisap udara dalam wadah diletakkanya 
komposit yang akan dilakukan proses pencetakan. Artinya, dengan divakumkan udara dalam wadah, maka udara yang ada di luar penutup plastik akan menekan ke arah dalam. Hal ini menyebabkan udara yang terperangkap dalam spesimen komposit dapat minimalkan. Pengujian dilakukan dengan uji tarik, kekerasan dan uji kemampuan balistik seperti pada gambar 2 dan 3.
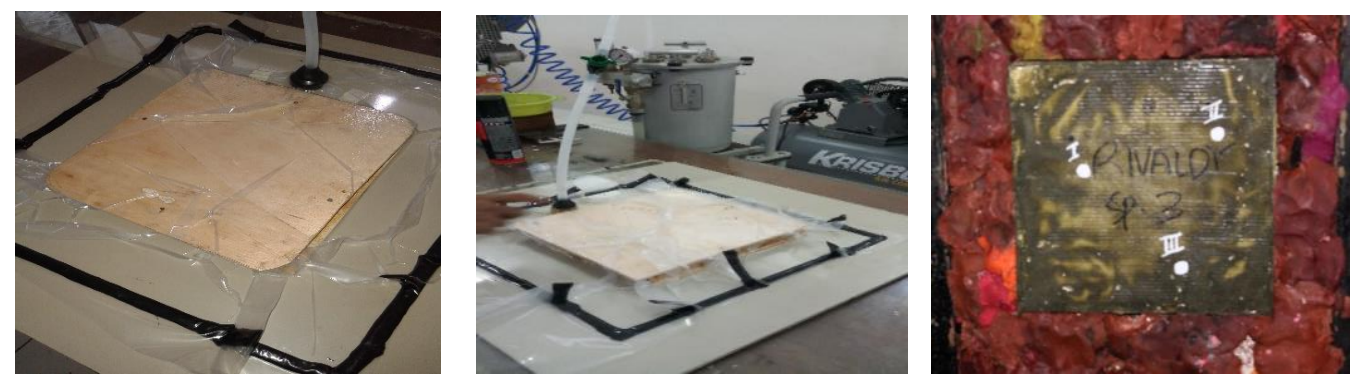

Gambar 1. Vacuum Bag dan Pemasangan Spesimen Uji Balistik
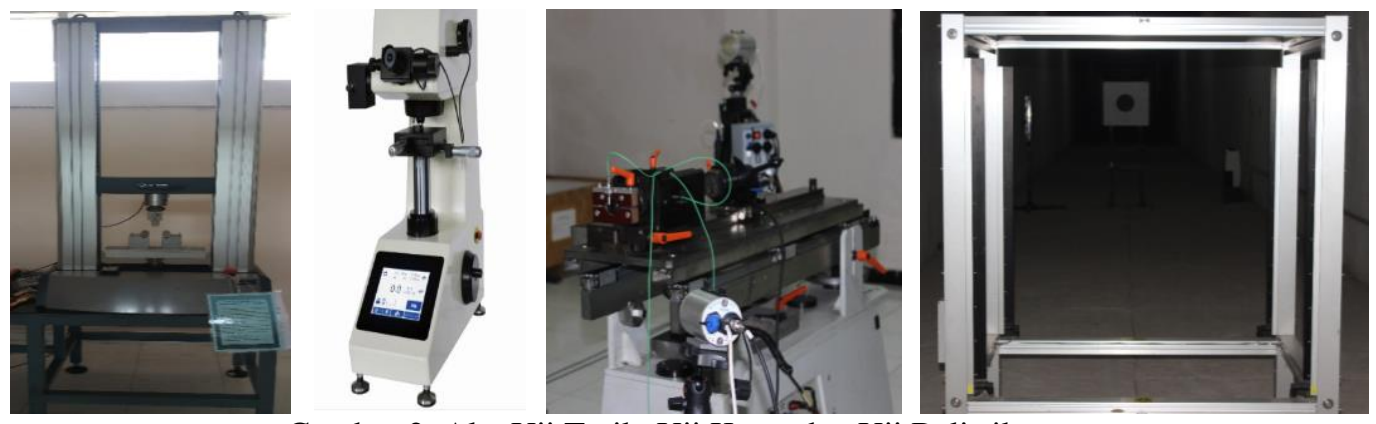

Gambar 2. Alat Uji Tarik, Uji Keras dan Uji Balistik

Sebelum membuat komposit persiapan yang dikumpulkan adalah menyiapkan alat dan bahan serta alkalisasi pada serat pelepah salak dengan $\mathrm{NaOH}$ 5\%. Siapkan semua alat dan bahan. Siapkan pelepah salak yang sudah dipotong $20 \mathrm{~cm}$ memanjang. Letakkan pelepah salak pada suatu wadah. Masukan $\mathrm{NaOH} 5 \%$ hingga semua permukaan terrendam. Tunggu selama 3 jam. Angkat pelepah salak dan jemur di bawah sinar matahari hingga kering. Langkah-langkah membuat komposit dengan Vacuum bag, yaitu: Siapkan alat dan bahan. Buat Komposit pada cetakan dengan menggunakan metode Hand Lay-Up terlebih dahulu. Letakkan komposit di bawah vacuum bag, setelah itu tutupi dengan peel ply dan tutupi dengan vacuum bag. Rekatkan vacuum bag dengan sealant tape sehingga tidak ada udara. Vakum terlebih dahulu supaya vacuum bag dapat merekat dan rapat dengan spesimen. Nyalakan vakum sehingga resin dapat terhisap dan mengalir mengenai spesimen. Lama waktu vakum selama kurang lebih 4 jam. Tahapan proses uji tarik, kekerasan dan kemampuan balistik adalah sebagai berikut: Pengujian dilaksanakan setelah 7 hari pengeringan spesimen. Uji Tarik menggunakan ASTM D 3039/3039M [18] sebanyak 2 spesimen dengan perbedaan komposisi pada setiap spesimen dimana spesimen pertama berupa resin $100 \%$ dan spesimen kedua dengan komposisi 70\% Resin, 10\% Filler SiC, 20\% serat salak. Uji kekerasan dilaksanakan pada 2 spesimen yang berbeda komposisi dimana komposisi spesimen sama dengan yang dilaksanakan pada pengujian tarik. Pengujian kekerasan menggunakan metode Vickers dengan alat Vicker Hardness Tester, pengujian dilaksanakan di 5 titk yang berbeda di setiap spesimennya. Pengambilan data diambil berdasarkan nilai uji dari masing masing spesimen. Uji kemampuan balistik dilaksanakan pada 4 spesimen yang memiliki komposisi yang berbeda-beda dengan menggunakan NIJ Standard 0101.06 dengan jarak $5 \mathrm{~m}, 10 \mathrm{~m}, 25 \mathrm{~m}$ dan $30 \mathrm{~m}$. 


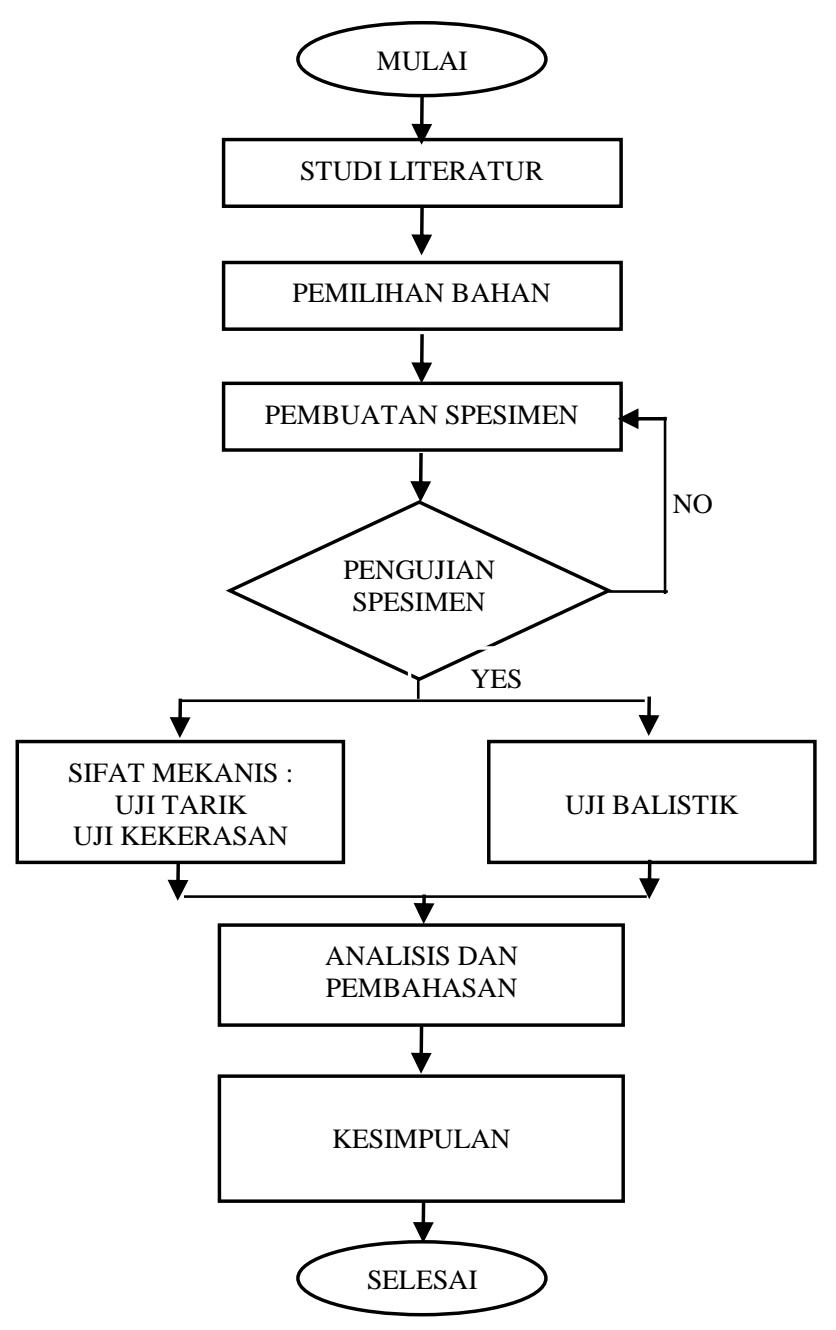

Gambar 3 Diagram Alir

\section{IMPLEMENTASI MODEL DAN PEMBAHASAN}

\section{A. Hasil}

Berdasarkan pengujian tarik terhadap material komposit dengan standar ASTM D 3039, maka didapatkan besarnya nilai tegangan maksimal dari tiap-tiap spesimen uji sesuai tabel 1,2 , 3 dan 4 sebagai berikut:

TABEL I

NILAI TEGANGAN

\begin{tabular}{|c|c|c|}
\hline \hline NO & $\begin{array}{c}\text { Spesimen 1 } \\
N / m^{2}\end{array}$ & $\begin{array}{c}\text { Spesimen 2A } \\
N / m^{2}\end{array}$ \\
\hline 1 & 17,48 & 20,7 \\
\hline 2 & 17,93 & 20,89 \\
\hline 3 & 18,23 & 22,79 \\
\hline Rata-Rata & 17,88 & 21,46 \\
\hline \hline
\end{tabular}


TABEL II

NILAI REGANGAN

\begin{tabular}{|c|c|c|}
\hline \hline NO & Spesimen 1 & Spesimen 2A \\
\hline 1 & 0,208 & 0,0875 \\
\hline 2 & 0,157 & 0,1235 \\
\hline 3 & 0,168 & 0,121 \\
\hline Rata-Rata & 0,1776 & 0,1106 \\
\hline
\end{tabular}

TABEL III

NiLAi MODULUS ELASTISITAS

\begin{tabular}{|c|c|c|}
\hline \hline \multirow{2}{*}{ NO } & $\begin{array}{c}\text { Spesimen 1 } \\
N / m^{2}\end{array}$ & $\begin{array}{c}\text { Spesimen 2A } \\
N / m^{2}\end{array}$ \\
\hline 1 & 84,03 & 236,57 \\
\hline 2 & 114,20 & 169,14 \\
\hline 3 & 108,51 & 188,34 \\
\hline Rata-Rata & 102,24 & 198,16 \\
\hline
\end{tabular}

TABEL IV

SIFAT MEKANIS SPESIMEN 1 DAN 2A

\begin{tabular}{|c|c|c|c|c|c|}
\hline \multicolumn{2}{|c|}{$\begin{array}{c}\text { Spesimen 1 } \\
(\text { Resin 100\%) }\end{array}$} & \multicolumn{2}{c|}{$\begin{array}{c}\text { Spesimen 2A } \\
\text { 70\% Resin, 10\% Filler (Sic) dan 20\% } \\
\text { Serat Pelepah salak }\end{array}$} \\
\hline Tegangan & Regangan & $\begin{array}{c}\text { Modulus } \\
\text { Elastisitas }\end{array}$ & Tegangan & Regangan & $\begin{array}{c}\text { Modulus } \\
\text { Elastisitas }\end{array}$ \\
\hline 17,88 & 0,1776 & 102,24 & 21,46 & 0,1235 & 198,16 \\
\hline \hline
\end{tabular}

Pelaksanaan pengujian kekerasan microvicker dilaksanakan dengan menggunakan load $0,5 \mathrm{~N}$ dan dwelling time 15 detik, spesimen yang diuji adalah spesimen dengan komposisi resin dan spesimen komposit dengan komposisi serat pelepah salak. Hasil nilai kekerasan spesimen 1 dan 2A sesuai tabel 4 dan 5 dibawah ini :

TABEL V

UJI KEKERASAN SPESIMEN 1

\begin{tabular}{|c|c|c|c|}
\hline \hline No & D1 & D2 & HVN \\
\hline 1 & 79,9 & 89,3 & 12,9 \\
\hline 2 & 87,9 & 55,7 & 17,9 \\
\hline 3 & 84,0 & 84,2 & 13,0 \\
\hline 4 & 68,3 & 73,9 & 18,3 \\
\hline 5 & 78,8 & 65,1 & 17,8 \\
\hline \multicolumn{3}{|l}{} \\
\hline Rata-Rata & \multicolumn{2}{|l}{} \\
\hline
\end{tabular}


TABEL VI

UJI KEKERASAN SPESIMEN 2A

\begin{tabular}{|c|c|c|c|}
\hline No & D1 & D2 & HVN \\
\hline 1 & 69,9 & 61,0 & 21,5 \\
\hline 2 & 68,3 & 65,7 & 20,6 \\
\hline 3 & 55,8 & 61,7 & 26,7 \\
\hline 4 & 58,0 & 60,7 & 26,2 \\
\hline 5 & 53,6 & 72,5 & 23,2 \\
\hline Rata-Rata & \multicolumn{3}{|r|}{} \\
\hline \hline
\end{tabular}

Maka didapatkanlah hasil bahwa pada spesimen 2A dengan komposisi $70 \%$ resin, $10 \%$ Filler $\mathrm{SiC}$ dan $20 \%$ serat pelepah salak memiliki nilai kekerasan yang lebih tinggi ketimbang spesimen 1 yang memiliki komposisi 100\% Resin. Dari penelitian ini dapat membuktikan bahwa sifat mekanis serat alam berupa pelepah salak lebih baik ketimbang resin sesuai dengan tabel 6 dibawah ini:

\begin{tabular}{|c|c|c|}
\hline \multicolumn{3}{|c|}{$\begin{array}{l}\text { TABEL VII } \\
\text { NILAI HVN }\end{array}$} \\
\hline \multicolumn{3}{|c|}{ NILAI HV } \\
\hline $\mathrm{NO}$ & $\begin{array}{c}\text { Spesimen } 1 \\
\text { (Resin) }\end{array}$ & $\begin{array}{c}\text { Spesimen 2A } \\
\text { (Komposit) }\end{array}$ \\
\hline 1 & 12,9 & 21,5 \\
\hline 2 & 17,9 & 20,6 \\
\hline 3 & 13,0 & 26,7 \\
\hline 4 & 18,3 & 26,2 \\
\hline 5 & 17,8 & 23,2 \\
\hline Rata-Rata & 15,98 & 23,64 \\
\hline
\end{tabular}

Sebelum uji tembak dilaksanakan, spesimen terlebih dahulu di pasangkan pada lesan uji dengan jarak yang sudah ditentukan. Setiap spesimen ditembak sebanyak 4 kali dengan menggunakan barrel dengan Amunisi kaliber 9 x 19 mm (MU-1 TJ). Jarak minimum perkenaan tembakan dengan sisi spesimen $+19 \mathrm{~mm}$ atau $1,9 \mathrm{~cm}$. (titik penembakan sudah diberikan pada spesimen). Jarak minimum antar perkenaan satu dengan yang lainnya adalah $100 \mathrm{~mm}$ atau $10 \mathrm{~cm}$. (titik penembakan sudah diberikan pada spesimen). Sebelum penembakan spesimen dimulai, agar dilakukan penembakan awal tanpa spesimen sebanyak 10 kali dengan jarak 25 meter. Kemudian paramater yang dibutuhkan adalah V0, V5, V10, V12.5, V15, dan V20. Di setiap spesimen sudah diberi penomoran I, II, III dan IV. Di setiap penembakan akan dicatat kondisi Temperature, Pressure dan Humidity. Bagian belakang spesimen diberi lilin malam. Backface Signature (BFS) Mengacu pada NIJ 0101.06 level IIA dan II dimana BFS kurang dari $44 \mathrm{~mm}$ dan peluru tidak tembus. Pengukuran BFS adalah dengan mengukur kedalaman lilin malam yang dipasang dibelakang spesimen uji, sebagai akibat dari hasil impak peluru yang mengenai spesimen tersebut. Sebelum uji balistik dilaksanakan pada setiap spesimen, agar dilakukan penembakan awal tanpa spesimen sebanyak 10 kali dengan jarak 25 meter. Kemudian paramater yang dibutuhkan adalah V0, V5, V10, V12.5, V15, dan V20. Dengan temperature sebesar $34^{\circ} \mathrm{C}$, tekanan $1 \mathrm{~atm}$ dan Humidity sebesar 57\%, Maka didapatkanlah hasil sesuai dengan tabel 7 berikut: 
TABEL VIII

KeCEPATAN PENEMBAKAN TANPA SPESIMEN

\begin{tabular}{|c|c|c|c|c|c|c|}
\hline \hline Index & $\mathbf{V 0}$ & $\mathbf{V 5}$ & $\mathbf{V 1 0}$ & $\mathbf{V 1 2 , 5}$ & $\mathbf{V 1 5}$ & $\mathbf{V 2 0}$ \\
\hline & $\mathbf{m} / \mathbf{s}$ & $\mathbf{m} / \mathbf{s}$ & $\mathbf{~} / \mathbf{s}$ & $\mathbf{~ m / s}$ & $\mathbf{~} / \mathbf{s}$ & $\mathbf{m} / \mathbf{s}$ \\
\hline 1 & 370,2 & 376,9 & 381,9 & 383,8 & 385,2 & 386,7 \\
\hline 2 & 405,6 & 399,3 & 393,2 & 390,2 & 387,3 & 381,6 \\
\hline 3 & 409,3 & 403,3 & 397,5 & 394,6 & 391,8 & 386,4 \\
\hline 4 & 407,9 & 401,5 & 395,4 & 392,4 & 389,4 & 383,7 \\
\hline 5 & 407,7 & 401,7 & 396,0 & 393,2 & 390,4 & 385,0 \\
\hline 6 & 403,4 & 397,0 & 390,8 & 387,7 & 384,8 & 379,1 \\
\hline 7 & 410,2 & 403,7 & 397,3 & 394,3 & 391,2 & 385,4 \\
\hline 8 & 404,8 & 398,5 & 392,5 & 389,6 & 386,7 & 381,0 \\
\hline 9 & 403,0 & 396,8 & 390,8 & 387,9 & 385,0 & 379,4 \\
\hline 10 & 407,6 & 401,2 & 395,0 & 392,0 & 389,1 & 383,3 \\
\hline Avg & $\mathbf{4 0 3 , 0}$ & $\mathbf{3 9 8 , 0}$ & $\mathbf{3 9 3 , 0}$ & $\mathbf{3 9 0 , 6}$ & $\mathbf{3 8 8 , 1}$ & $\mathbf{3 8 3 , 2}$ \\
\hline
\end{tabular}

Setelah dilaksanakan pelaksanaan penembakan sebanyak 10 kali tanpa menggunakan spesimen pada setiap jarak yang berbeda, dapat diambil rata-rata pada setiap jarak penembakan. Hasil tersebut kemudian akan dijadikan patokan untuk penembakan pada spesimen yang lainnya. Dapat diperhatikan bahwa setiap kenaikan jarak $5 \mathrm{~m}$, kecepatan rata-rata yang dihasilkan akan turun sebesar $5 \mathrm{~m} / \mathrm{s}$. Maka pada jarak 25m akan didapat kecepatan sebesar 378m/s. Dapat dilihat pada grafik Gambar 4 berikut:

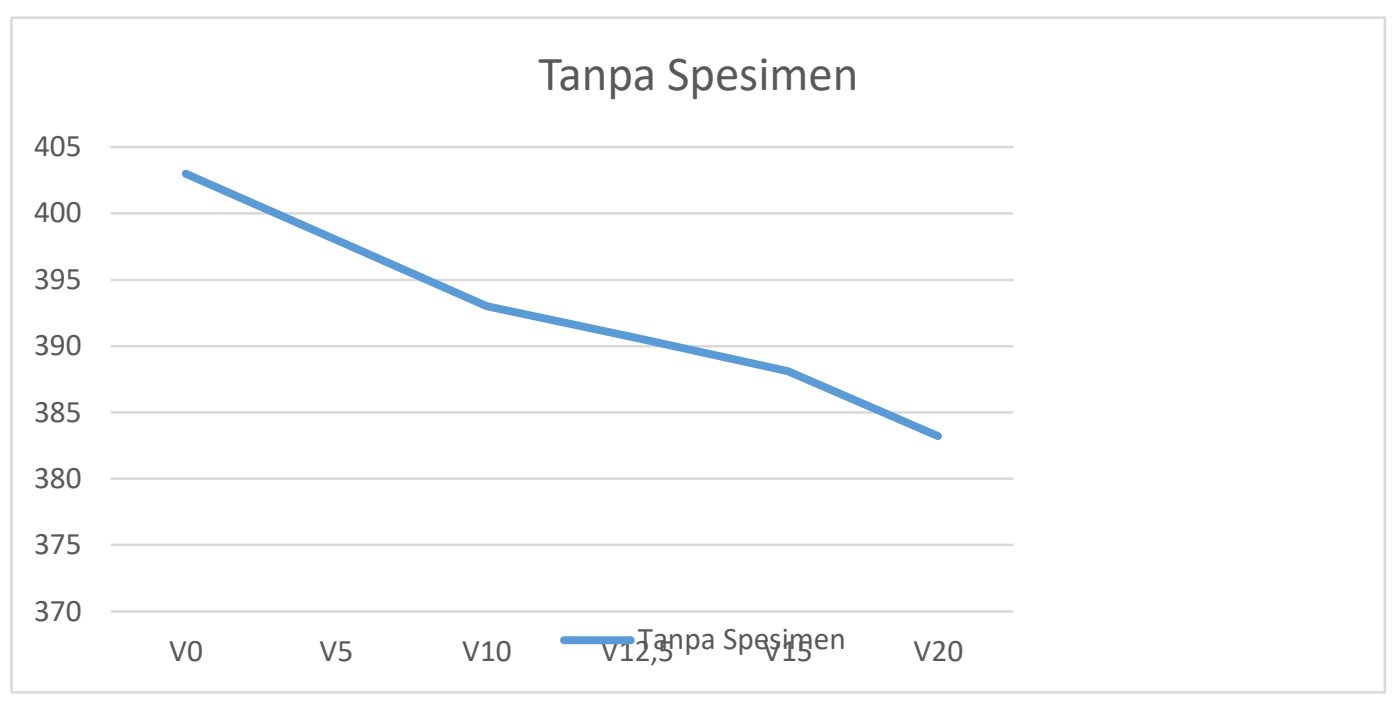

Gambar 4. Grafik Tanpa Spesimen

Menurut standar NIJ bahwa $V_{0}$ untuk level IIA adalah $373 \mathrm{~m} / \mathrm{s}$ dengan toleransi $\pm 9.1 \mathrm{~m} / \mathrm{s}$, dari hasil penembakan yang dilakukan diperoleh kecepatan $373 \pm 9.1 \mathrm{~m} / \mathrm{s}$ terjadi pada jarak $25 \mathrm{~m}$ sehingga artinya jarak $25 \mathrm{~m}$ tersebut merupakan $V_{0}$ yang dilakukan dalam pengujian level IIA ini, sehingga jarak penembakan level IIA adalah $25 \mathrm{~m}+5 \mathrm{~m}=30$ meter. Sedangkan $V_{0}$ untuk level II adalah $398 \mathrm{~m} / \mathrm{s}$ dengan toleransi $\pm 9.1 \mathrm{~m} / \mathrm{s}$, dari hasil penembakan yang dilakukan diperoleh kecepatan $398 \pm 9.1 \mathrm{~m} / \mathrm{s}$ terjadi pada jarak $5 \mathrm{~m}$ sehingga artinya jarak $5 \mathrm{~m}$ tersebut merupakan $V_{0}$ yang dilakukan dalam pengujian level II, sehingga jarak penembakan level II adalah $5 \mathrm{~m}+5 \mathrm{~m}=10$ meter. Dalam penelitian ini juga dilakukan penembakan dengan riil jarak $5 \mathrm{~m}$ dimana standar NIJ menyatakan penembakan dilakukan pada jarak 5 meter (ini dengan asumsi tanpa memperhatikan $V_{0}$ yang terjadi). 
Hasil penelitian ini sudah dibuktikan konsep fungsi serta karakteristiknya secara analitis dan eksperimental dalam lingkungan laboratorium sesuai standar yang ditetapkan yaitu NIJ level II dan IIA, sehingga penelitian ini sudah masuk dalam Technology Readiness Level 4.

Berdasarkan hasil pengujian terhadap setiap spesimen yang memiliki komposisi yang berbeda berupa pengujian tarik dan kekerasan yang dilaksanakan di Departemen Aeronautika dan pengujian balistik yang dilaksanan di Depohar 60 Madiun, didapatkanlah hasil dari setiap pengujian seperti ditujukan pada tabel 8 berikut:

TABEL I

HASIL UJI BALISTIK

\begin{tabular}{|c|c|c|c|c|c|c|}
\hline \multicolumn{7}{|c|}{ KEMAMPUAN BALISTIK } \\
\hline \multirow[t]{2}{*}{ NO } & \multirow[t]{2}{*}{ SPESIMEN } & \multicolumn{4}{|c|}{ JARAK PENEMBAKAN } & \multirow[t]{2}{*}{ KETERANGAN } \\
\hline & & $5 \mathrm{~m}$ & $10 \mathrm{~m}$ & $25 \mathrm{~m}$ & $30 \mathrm{~m}$ & \\
\hline 1. & $\begin{array}{c}\text { Spesimen 2B } \\
\text { (70\% resin, } \\
10 \% \text { Filler } \\
\text { SiC dan } 20 \% \\
\text { serat pelepah } \\
\text { salak) }\end{array}$ & Tembus & Tembus & Tembus & Tembus & $\begin{array}{c}\text { Tidak Memenuhi } \\
\text { Standar NIJ Level } \\
\text { IIA }\end{array}$ \\
\hline 2. & $\begin{array}{c}\text { Spesimen } 3 \\
\text { (70\% Resin, } \\
10 \% \text { Filler } \\
\text { SiC, } 20 \% \\
\text { Kevlar) }\end{array}$ & Tembus & Tembus & $11,86 \mathrm{~mm}$ & $6,26 \mathrm{~mm}$ & $\begin{array}{c}\text { Memenuhi } \\
\text { Standar NIJ Level } \\
\text { IIA }\end{array}$ \\
\hline 3. & $\begin{array}{c}\text { Spesimen } 4 \\
\text { (70\% Resin, } \\
10 \% \text { Filler } \\
\text { SiC, } 10 \% \\
\text { Serat Pelepah } \\
\text { Salak, 10\% } \\
\text { Kevlar) }\end{array}$ & Tembus & Tembus & Tembus & Tembus & $\begin{array}{c}\text { Tidak Memenuhi } \\
\text { Standar NIJ Level } \\
\text { IIA }\end{array}$ \\
\hline 4. & $\begin{array}{c}\text { Spesimen } 5 \\
\text { (70\% Resin, } \\
10 \% \text { Filler } \\
\text { SiC, } 10 \% \\
\text { Serat Pelepah } \\
\text { Salak, 10\% } \\
\text { Kevlar dan } \\
\text { AL 7075) }\end{array}$ & $\begin{array}{l}\text { Tidak } \\
\text { Tembus }\end{array}$ & $\begin{array}{l}\text { Tidak } \\
\text { Tembus }\end{array}$ & $\begin{array}{l}\text { Tidak } \\
\text { Tembus }\end{array}$ & $\begin{array}{c}\text { Tidak } \\
\text { Tembus }\end{array}$ & $\begin{array}{c}\text { Memenuhi } \\
\text { Standar NIJ Level } \\
\text { IIA \& II }\end{array}$ \\
\hline
\end{tabular}




\section{KESIMPULAN}

Syarat komposit berhasil adalah sifat mekanis komposit lebih besar dari sifat mekanis resin yang digunakan. Dalam penelitian ini dihasilkan kekuatan Tarik komposit serat pelepah salak (Spesimen 2A) sebesar 21,46 N/mm², lebih besar dari kekuatan Tarik resin (spesimen 1) sebesar $17,88 \mathrm{~N} / \mathrm{mm}^{2}$. Selain itu nilai kekerasan komposit sebesar 23,64 HV, lebih besar dari nilai kekerasan resin sebesar 15,98 HV. Pengujian balistik pada Spesimen Komposit 2B dengan komposisi $70 \%$ resin, 10\% Filler SiC dan 20\% serat pelepah salak dan Spesimen Komposit 4 dengan komposisi $70 \%$ resin, 10\% Filler SiC, 10\% serat Kevlar dan 10\% serat pelepah salak diperoleh hasil penembakan jarak $5 \mathrm{~m}, 10 \mathrm{~m}, 25 \mathrm{~m}$ dan $30 \mathrm{~m}$, dimana semua peluru dapat menembus spesimen. Maka kedua spesimen ini tidak dapat memenuhi standar NIJ level IIA.Pengujian balistik pada Spesimen Komposit 3 dengan komposisi 70\% resin, 10\% Filler SiC dan 20\% serat Kevlar dan Spesimen Komposit 5 dengan komposisi 70\% resin, 10\% Filler SiC, $10 \%$ serat Kevlar, 10\% serat pelepah salak dan AL7075-T6 diperoleh hasil penembakan pada Spesimen 3 jarak $30 \mathrm{~mm}$ memiliki BFS 6,26 mm, jarak $25 \mathrm{~m}$ memiliki BFS 11,86 mm, jarak 10 $\mathrm{m}$ dan jarak $5 \mathrm{~m}$ peluru menembus spesimen sedangkan pada spesimen 5 diperoleh hasil penembakan jarak $25 \mathrm{~m}$ memiliki BFS $0 \mathrm{~mm}$, jarak $10 \mathrm{~m}$ memiliki BFS $0 \mathrm{~mm}$ dan jarak $5 \mathrm{~m}$ memiliki BFS $0 \mathrm{~mm}$. Maka kedua spesimen ini dapat memenuhi Standar NIJ level IIA.

\section{REFERENSI}

[1] Mokhamad Azissyukhron, Syarif Hidayat, Perbandingan Kekuatan Material Hasil Metode Hand Lay-up dan Metode Vacuum Bag Pada Material Sandwich Composite, Jurusan Teknik Mesin,Politeknik Negeri Bandung,Bandung.

[2] Liska Triyastiti, Didik Krisdiyanto : Isoalasi Nanokristal Selulosa Dari Pelepah Pohon Salak Sebagai Filler Pada Film Berbasis Polivinil Alkohol (PVA), Indonesian Journal of Material Chemistry Vol. 1, No. 1, 2018 ISSN 2654-3737 (print), ISSN 2654-556X (online).

[3] Structural Composite Materials, F.C. Campbell, ASM International, Materials Park, Ohio.

[4] Rodiawan, Suhdi, Firlya Rosa, Analisa Sifat-Sifat Serat Alam Sebagai Penguat Komposit Ditinjau Dari Kekuatan Mekanik, TURBO Vol. 5 No. 1. 2016.

[5] Muhammad Luthfi, Muhammad Abdul Ghofur (2020) 'Analisis Sifat Mekanik, Mikrostruktur dan Komposisi Komposit Carbon Epoxy Hasil Metode Hand Lay Up dan VARTM' , AAU Journal of Defense Science and Technology (JDST) Vol. 9, No.1, April 2020, pp. 9-18 ISSN: 2086-5805.

[6] Muhammad Irvan Hasyim, Muhammad Abdul Ghofur (2020) 'Analisis Variasi Fraksi Volume Serat Dan Perlakuan Alkali Terhadap Kekuatan Tarik Dan Bending Komposit Serat Sisal”, AAU Journal of Defense Science and Technology (JDST) Vol. 9, No.2, July 2020, pp. 107-114 ISSN: 2086-5805

[7] Seno Darmanto, Sarwoko, Eko Julianto Sasono, Yusuf Umardani, dan Sriyana, Karakterisasi Perlakuan Awal Serat Pelepah Salak Untuk Meningkatkan Kekuatan Mekanik. Universitas Dipenogoro.

[8] Annisa Angelia, Muhammad Abdul Ghofur, Arif Djoko Nugroho, Purwadi, Purnomo Herlambang (2020) "Analisis Kekuatan Tarik, Bending, Mikrostruktur, Komposisi dan Kemampuan Redam Suara Komposit Serat Pelepah Pisang Menggunakan Metode Vacuum Assisted Resin Infusion', Prosiding Seminar Nasional Teknologi Informasi dan Kedirgantaraan SENATIK 2020, Vol. VI, pp.67-79 ISBN 978-602-52742-1-3

[9] Fernanda Santos da Luz, Fabio da Costa Garcia Filho, Michelle Souza Oliveira, Lucio Fabio Cassiano Nascimento and Sergio Neves Monteiro (2020), Composites with Natural Fibers and Conventional Materials Applied in a Hard Armor: A Comparison, Polymers 2020, 12, 1920; doi:10.3390/polym12091920.

[10] J. Naveen, K. Jayakrishna, Mohamed Thariq Bin Hameed Sultan and Siti Madiha Muhammad Amir (2020), Ballistic Performance of Natural Fiber Based Soft and Hard Body Armour- A Mini Review, Frontier in materials, December 2020, Volume 7, article 608139

[11] Harun N. Beliu, Yeremias M. Pell, Jahirwan Ut Jasron, Analisa Kekuatan Tarik dan Bending pada Komposit Widuri-Polyester, LONTAR Jurnal Teknik Mesin Undana, Vol. 03, No. 02, Oktober 2016.

[12] Yopi Handoyo, Perancangan Alat Uji Impak Metode Charpy Kapasitas 100 Joule, Jurnal Imiah Teknik Mesin, Vol. 1, No. 2, Agustus 2013 , Universitas Islam 45, Bekasi.

[13] Daud Simon Anakottapary, Tjokorda Gde Tirta Nindhia , Interaksi antara Proyektil dan Komposit Polimer diperkuat Butiran Silikon Karbid (SiCp) dan Serat Karbon pada Pengujian Balistik /Jurnal Ilmiah Teknik Mesin Vol. 4 No.2. Oktober 2010 (99-105).

[14] Maulidya Ilyas, Mikroskop Pemindai Elektron (Scanning Electron Microscope)-SEM, dilihat 17 November 2020

[15] https://www.academia.edu/35657579/Mikroskop_pemindai_elektron_Scanning_Electron_Microscope_SEM 
[16] Mawardi Indra dan Lubis Hasrin, Proses Manufaktur Plastik Dan Komposit Edisi Revisi, Yogyakarta, Penerbit Andi .

[17] Satrio febriyanto (2011), 'Penggunaan Metode Vacuum Assisted Resin Infusion Pada Bahan Uji Komposit Sandwich Untuk Aplikasi Kapal Bersayap WISE-8', Universitas Indonesia.

[18] ASTM International, Designation: D 3039/D 3039M - 00, Standard Test Method for Tensile Properties of Polymer Matrix Composite Materials.

[19] Michael B. Mukasey, Jeffrey L. Sedgwick, David W. Hagy (2008) "Ballistic Resistance of Body Armor NIJ Standard-0101.06", U.S. Department of Justice Office of Justice Programs National Institute of Justice

[20] P. Sugandhan, S.Thirumavalavan (2017), Ballistic Analysis of Composite Materials, International Journal of Computational Engineering Research (IJCER), ISSN (e): 2250 - 3005, Volume, 07,| Issue, 10, October - 2017.

[21] Peraturan Presiden Republik Indonesia No. 38 tahun 2018 tentang Rencana Induk Riset Nasional tahun 20172045

[22] Peraturan Menteri Riset, Teknologi, Dan Pendidikan Tinggi Republik Indonesia Nomor 38 Tahun 2019 Tentang Prioritas Riset Nasional Tahun 2020-2024 disebutkan bahwa salah satu bidang

[23] Peraturan Menteri Riset, Teknologi, Dan Pendidikan Tinggi RI No. 42 Tahun 2016 tentang Pengukuran dan Peneteapan Tingkat Kesiapterapan Teknologi ( Technology Readiness Level) 